\title{
The Relationship between Ecological Environment Protection and Social Development to Chinese Resource-exhausted Cities
}

\author{
Han Quanfang ${ }^{1} *$ \\ School of Public Management \\ Yunnan University of Economics and Finance \\ Kunming, P.R.China 650221 \\ hqfang666@163.com \\ Yu Jianlei $^{3}$ \\ School of Public Management \\ Yunnan University of Economics and Finance \\ Kunming, P.R.China 650221 \\ yujianlei123@sina.com
}

\begin{abstract}
The most Inclusive welfare of people is good ecological environment, ecological environment protection and coordination mechanism of development are keys to promote Resource-exhausted cities. The article analyze development and drain of mineral resources, and these factors Influence society a lot. Build on researching, we suppose that construct Intergovernmental cooperation mechanism, prevention of geological hazard mechanism, ecological compensation mechanism, ecological environment responsibility mechanism are ecological environment protection and social development to Chinese Resource-exhausted cities' important points.
\end{abstract}

Keywords-Resource-exhausted cities; Ecological environment protection; Harmonious development; Coordination mechanism

\section{INTRODUCTION}

Resource-exhausted cities means when mineral resources exploitation come into end-stage, cities' recoverable reserves come up to $70 \%$. The relationship between ecological environment protection and social development to Chinese Resource-exhausted cities become a prominent problem, for example, Ruhr Industrial Base and Lorraine. In 2008, 2009 and 2012, Chinese government confirm 69 resource-exhausted cities or counties.[1] Resource-exhausted cities' resource development brings a lot of problems, like environmental pollution, ecological deterioration, lack of sources of livelihood, conflict region and so on. Today's government attaches great importance to these problems.

At present, the resource exhausted cities in China generally are facing serious environmental pollution and ecological destruction and other issues due to excavate for resources long time and high strength, such as over exploitation led to surface subsidence, land resources, water resources and atmosphere environment is seriously polluted, mountain coal mining leads to vegetation is destroyed and so on. The causes of the

\author{
Ge Shaolin ${ }^{2}$ \\ School of Public Management \\ Yunnan University of Economics and Finance \\ Kunming, P.R.China 650221 \\ geshaolin72@163.com
}

ecological environment governance problem of resource-based city are complex and the task is arduous. Both historical debts, but also new pollution emissions. both the enterprise evade responsibility, but also the government inaction; both the problem of system and mechanism, but also technical problems; both the problem of short term cure, but also the problem of long term treatment.

\section{LITERATURE REVIEW}

A lot of foreign countries' focus on mine eco-environment comprehensive treatment and interest groups. Started in the 1970 of the 20th century, western environmental sociology and sociology of natural resources focused on relationship between natural environment and society, R.E.Dunlap and $\mathrm{W} \cdot \mathrm{R} \cdot \mathrm{Caton}(1978)$ theorize on "new ecological paragidm" and "Competition environment of Three - dimensional features", and Foster(1980) theorize on Socio-ecological "metabolic" theory.[2]The US' rural sociology have a Long-term research interest on the relationship between rural communities and resource issues, Marsh(1987) researched on residents' a sense of community of coal town[3], Gill(1990) theorize on social Interaction of mine area, In the US, have more than 100,000 Ghost Town because depletion of mineral resources (Hall Shawn, 1998). ${ }^{[4]}$ "The mining lease act", mineral resources investigation and appraisal, reclaiming system all point that recovery of ecological environment in mine area. Australia plans to implement the framework through the development of lasting value of mining area construction, Ghana asked Congress to discuss new mining laws to consider when mining on communities affected, compensation, rehousing and so on. Affected by mining of Norway, and Chile, and Venezuela and other countries, through the establishment of savings fund to safeguard the sustainable development of mining areas, and so on.
This article sported by Chinese National Social Science Foundation(13CSH088). Ministry of Education, Humanities and Social Sciences Youth Fund(12YJC840007).Ministry of Education, Humanities and Social Sciences western and Border areas Fund(11XJA840002). 
Today's research on ecological environment protection and human development tend to deal with environment and society. $\mathrm{Lu}$ Shuhua(1994) discuss the relevant to personal power resource and environment welfare,[5] Ma Rong(1995) focus on relationship between utilization of grassland resources and pastoral and social development,[6] Zhou Changcheng think The sustainable development is mining communities only choice,[7] Ma Guoqing(2001) study Mongolian lifestyle culture, religion and ethics associated with the natural environment, [8]Xu Kangning(2006) empirical "resource curse" effect on the resource highlighted.[9]Hong Dayong(2013) think that inherent in the construction of ecological civilization, including ecological construction and social development, its essence is in social construction and promoting eco-construction,[10] Shi Guoqing(2014) reference theories of sustainable livelihoods, analysis of Dongping Lake ecological environment caused by essence fracture of the livelihood of the fishermen, Bao Zhiming(2014) think rationalize West ecological environment protection and ecological civilization construction of the relationship between economic and social development is an important breakthrough, [11]Zheng Shaoxiong(2014) proposed fate of the grassland communities depend on external forces finer space on both sides with the community consultation mechanism.[12]

To sum up, from the perspective of social operation, China mining "environmental-social" relationship of social benign operation and coordinated development posed a serious threat, ecological and environmental problems due to mineral resource development and contradiction of livelihood issues, cutting requires the use of sociological theories, perspectives and methods research on mining ecological environment protection and human development coordination mechanisms, improve the livelihood of the ecological situation, this is a problem to be considered and valued.

\section{Analysis on the Relationship Between}

RESOURCE-EXHAUSTED URBAN ECO-ENVIRONMENT AND PEOPLE'S LIVELIHOOD

\section{A. Theoretical basis for the study of environment - society relationship}

A good ecological environment is the fundamental basis for human and social sustainable development. The essence of environmental issues is that the harmony between man and nature is broken, which is the objective consequence of the social system to keep erosing and destroying the ecosystem. From Parker's "Social Complex" theory, [13] to McKenzie's theory of centralization, decenralization, invasion, and succession, they can reveal the change process of mines; Hawley emphasizes on the interdependence of community, namely the symbiotic relationship or symbiosis, and the important reason for system changes is that the reduction of natural resources cannot be replaced; Duncan's POET (population, organization, environment, and technology) ecological complexity theory; Coleman and Saunders' community conflict theory. These theories can reveal basic problems of environmental and social interaction in the process of mineral resources development, such as background, causes, mechanisms, processes, consequences and prospects, environmental problems related factors including social characteristics, social causes, social processes, social impact, and the type of environmental behavior and its impact. The study on the relationship between them has laid a theoretical basis for environmental protection and improving mutual promotion and common development with social progress.

\section{B. Effect of mineral resources exploitation upon the formation of resources-based cities}

Mineral resources mining is the direct cause for the generation of mining towns. Without exception, the rise of mining cities is due to the discovery and exploitation of some kind of mineral resources, which is more prominently reflected in the geographically remote mining cities. According to preliminary studies and incomplete statistics, more than 50 ancient mining cities had at least been found in China in the late Neolithic Period or Pottery Age. [14] Ruins of the ancient copper mines were found in Daye, Hubei, Ruichang, Jiangxi, Tongling, Anhui and other places, becoming the first batch of mining cities discovered in China after the Neolithic Period. Mining development accelerated the urbanization of mining cities. Construction of mining cities is closely related to mining development. The construction of mining cities is closely connected to the prosperity and activeness of mining development activities in the same historical periods. It was true in the ancient times and truer in modern times. [14]

San Francisco is a city coming out of the Gold Rush. When gold was discovered in San Francisco in 1848, it was only a small village with a few hundred people. But with the emergence of the Gold Rush, San Francisco had become a city with a population of 25,000 in 1850 . Its urban population rose to 50,000 in 1856. Its urban size developed in just eight years may require New York to take about 190 years to reach. [15]

\section{Effect of mineral resources exhaustion upon the decline of resources-based cities}

In many Chinese and foreign mining cities, their spontaneous changing modes almost always followed the path of building a city due to mining development and declining due to exhaustion of mineral resources. The main reason is that all productions in these cities rely on and serve the mining industry. Therefore, once the mineral resources are exhausted, all industries will be affected, such as languished businesses, economic depression, decrease of community attachment, and rapid reduction of community population. The decay of mining communities is attributed to the combined action of external and internal forces (causes), but the internal cause is the main reason for the decline of the mines. The external cause is reflected in that the aggregation of a large population in the short term accelerates the rate of mineral resource exhaustion and that there is a lack of non-mining industries. While the internal cause is reflected in that the absence of various systems and organizations in mining communities leads to social anomie, and frequent rancor-based conflicts and 
reduction of belonging sense result in the exhaustion of mineral resources and decay of cities. [16]

"Ghost Towns" appeared in the US. In the second half of the 19th century, the development of the mining industry reached an unprecedented scale in the western United States. A large number of floating people gathered in the places where mineral resources were discovered and then hundreds of thousands of mines sprung up. However, with the exhaustion of mineral resources, a considerable part of mining communities were abandoned or damaged to become deserted cities, which are known as "Ghost Towns". "Ghost Town" almost all appeared in the areas where the mining industry was prevailing, such as Colorado, Arizona, Nevada, Montana, California and other places in the US. A historian found in his investigation in Elko County in Nevada that, a total of 106 "ghost towns" were abandoned because of Gold Rush, including 26 in the northwest of the county, 26 in the northern and central parts, 17 in the northeast, 21 in the southwest, and 16 in the southeast. [17]

\section{THE CONSTRUCTION OF ECOLOGICAL ENVIRONMENT PROTECTION AND COORDINATION MECHANISM OF DEVELOPMENT IN RESOURCE-EXHAUSTED CITIES}

According to Social Function Theory, Today's Chinese "Environment-society" relations have a serious threat on benign operation and coordinated development of the society. To relive this threat, Self-evolution can not be accepted, we must reflections on mechanism of the running of our society Immediately, operating mechanism of adaptation and improvement of our society, through elaborate people and society's autonomy to promoting improvements in environmental quality and coordinate "Environment-society" relations.[18] take eco-efficiency as core of the socio-economic development plan, and implement details, these project need relevant government department work together, especially some traditional management department, have to abandon some thinking of local benefit. Setting a group of policy and management system, which are Security requirements of ecological restoration and construction objectives. In Western Development, there are a set of problems about Ecological protection and construction, such as Large-scale investment, Immigration, so we also need strong policy support.[19]

The ecological environment protection and development coordination mechanism of resource-exhausted cities must base on theories, social integration, social justice and sustainable development, Chinese characteristics of the socialist ecological civilization must be uphold, discover coordination mechanism of ecological environment protection and people's livelihood development should under the theorize a good ecological environment. The mine area consist of ecological environment system, mineral resources exploitation system, socio-economic system, alleviate environmental problems, contain continued deterioration of the environmental situation, to promote the coordination of environmental and social relations, we must through a set of adjustment and change of social operation mechanism, It is urgent to seek and establish a mechanism to solve the problems in the development of the mining area by the government, mineral company, residents and non-governmental organizations.

Good ecological environment is an important condition for the sustainable development of economy and society, and is the fundamental basis for a nation's survival and development. It is the basic policy of national development to insist on saving resources and protect the environment. It is related to the vital interests of the masses of the people and the survival and development of the Chinese nation. Therefore, it is necessary to establish the government cooperation mechanism, contradiction coordination mechanism, mechanism of the prevention and control of geological disasters, ecological compensation mechanism, mechanism of ecological restoration, ecological and environmental protection responsibility investigated mechanism and supervision mechanism, green industry substitution mechanism series mechanism to promote mining employment and re employment, relocation of geological hazards, social security and medical and health services, and create a safe and harmonious living environment for the production. The social construction and promoting ecological construction, so as to realize the construction of ecological civilization in mining area.

\section{CONCLUSION}

Research on resource-exhausted cities' the coordination mechanism between ecological environment protection and people's livelihood development can not only be satisfied with the establishment of the mechanism, but through the study of its internal relations, to find the way to achieve the basic purpose of the ecological civilization construction in mining areas and countermeasures. Focus on the concept of the development of the mining area, the country's ecological civilization construction goals to the mining area itself, adhere to the "sustainable development" and "human centered" concept of development; The development of social policy in the mining area, the macro national policy and local policy coordination, supporting, in the macro policy to reflect the spirit of the development of the mining area; Explore mining areas engage in community development path, through "participate - empowerment - self development "model, the formation of a government dominant mining revenue, mining companies directly supports the development of the mining area, multi stakeholder involvement pattern of development of the mining area. To establish the benefit sharing and ecological environment compensation model of mining area resources, to solve the conflict of interests and environment, and to promote the coordinated development of population, resources, economy and society in the mining area.

Resource exhausted city makes the resource-based city faced with many serious problems of environmental pollution and ecological damage due to excavate for resources long time and high strength, a serious threat to the survival and development of resource type city. It is a serious threat to the 
survival and development of the resource-based city. Fundamentally, the ecological environment is a public product with external economy. It has a large investment and high social benefit, but the economic benefit is very low, even to zero. From the perspective of public management theory, the government can not shirk its responsibility. In the specific governance, the government should clarify responsibilities, overall design, perfect policy, and play a positive role in enterprises, individuals and other parties. The government should also make the efforts to promote green development, cycle development and low carbon development to solve the problems of ecological environment. Finally the government can achieve a virtuous cycle of economic development and ecological protection.

Ecological remediation of the resource exhausted cities in China must be based on the framework of social, economic and environmental coordinated development. At the same time, economic development also needs to establish a strategy to deal with environmental pollution and ecological destruction. On the one hand, to restrict or prevent new pollution, prevent the superposition of the factors of environmental pollution and pollution effect; on the other hand, increase the existing pollution governance, enhance the ecological carrying capacity of the environment. Of course, in the short term, the pollution needs governance. In the long term, need to carry on the strategic adjustment of the economic structure, vigorously develop alternative industries, promote the optimization and upgrading of industrial structure.

\section{REFERENCES}

[1] http://baike.baidu.com/link?url=IPH2bZqg2Dh8Mf5YCMvKt6hhASV KaeWojBd494J2Pu474Q9VPu08OUyKkNA0MdmBMnt7cIq5R_URQ OKM3 4 X7

[2] John Hannigan. Environmental Sociology Second Edition[M], Translation by Hong Dayong . China Renmin University Press, 2009.

[3] Marsh B.Continuity and decline in the anthracite towns of Pennsylvania, Annals of the Association of American Geographers, $1987,3$.

[4] Hall.Shawn, Old heart of Nevada: ghost towns and mining camps of Elko County, University of Nevada Press, 1998.

[5] Lu SHuhua. Sociological Research on urban ecological environmental problems[J]. Sociological research.1994(11).

[6] Ma Rong. Utilization of grassland resources and social development in pastoral areas[M]. Tianjin People Press.1995.

[7] Zhou Changcheng,Liu Zhongrong,Wang Ping. Sustainable development:The only choice of the mining community[J]. Environmental Science and Technology.1994(04).

[8] Ma Guoqing. Grassland ecology and the folk environmental knowledge of Mongolia[J]. Inner Mongolia Social Sciences.2001(01).

[9] Xu Kangning,Han jian."Resource curse" effect of regional economy in China: Another explanation to regional disparity[J]. Economist.2005(06).

[10] Hong Dayong. New thoughts on China's environmental problems and the construction of ecological civilization[J]. Exploration and Contending . 2013(10)

[11] Bao Zhiming. The construction of ecological civilization in the view of Sociology[J]. Inner Mongolia Social Sciences.2004(01).

[12] Zheng Shaoxiong. Spatial process and local reconstruction of grassland community:Analysis approach based on "local space tension"[J]. Opening times2013(06).

[13] R.E.Park. Urban Sociology: a study of Chicago school[M]. Zheng Yefu, Song Junling translation. The Commercial Press.2012.
[14] Zhang Yicheng. Introduction to mining cities[M].China mining industry.2005(07).p6

[15] Bayard Steele.Western Development Report (1607-1890)[M].Zhang Yujiu translation.Guangming Daily Press.1988.

[16] Han Quanfang. Dynamic analysis of population and social changes in mine community : a case study of "ghost town" in the United States[J].Southern population.2008(03),P33.

[17] ]Hall.Shawn, Old heart of Nevada: ghost towns and mining camps of Elko County, University of Nevada Press, 1998, p210.

[18] Zheng Hangsheng. The relationship between environment and society and social operation[J].Gansu Social Sciences.2007(01).

[19] Zeng Hui, Gao Lingyun, Li Shujuan.The strategy of ecological comprehensive treatment in Dongchuan area of Yunnan province[J]. China Environmental Science.2002(01). 